\title{
Firearm Suicides in the Elderly: A Narrative Review and Call for Action
}

\author{
James H. Price ${ }^{1}$. Jagdish Khubchandani ${ }^{2}$ \\ Accepted: 9 January 2021 / Published online: 5 February 2021 \\ (c) The Author(s), under exclusive licence to Springer Science+Business Media, LLC part of Springer Nature 2021
}

\begin{abstract}
Firearm suicides are one of the leading causes of death for older Americans. The purpose of this review is to explore the risk factors associated with suicides in the elderly, provide an overview of the epidemiology of firearm-related suicides in older Americans, and explore methods of preventing firearm suicides in the elderly. The vast majority (70\%) of elderly suicides in the U.S were committed using a firearm. Elderly firearm suicides have increased by $49 \%$ between 2010 and 2018 , disproportionately affecting white males. Yearly firearm suicides in the elderly ranged from 4,276 in 2010 to 6,375 in 2018. In 2018, the rate of elderly male firearm suicides was $24.96 / 100,000$ compared to a rate of 1.92/100,000 for elderly females, a rate ratio of 13 to 1 for males compared to females. The primary risk factors for elderly firearm suicides seem to be physical illnesses, mental illnesses, and social factors. Older Americans engage in suicidal behaviors with greater planning and lethality of intent than do young adults. Of all the strategies to prevent suicides with firearms, the most efficacious measures based on current research seem to be state firearm legislation and improving mental healthcare, but these effects are not specific to the elderly. Strengthening state firearm laws and improving mental healthcare for the elderly may have promise in preventing elderly firearm-related suicides. Additional implications for practice and research are discussed in this review.
\end{abstract}

Keywords Suicide $\cdot$ Injury $\cdot$ Mortality $\cdot$ Self-Harm $\cdot$ Elderly $\cdot$ Geriatrics $\cdot$ Firearms

\section{Introduction}

On a typical day, more than 100 Americans die by suicide, it is one of the leading causes of death in the United States [1]. Half of the suicides are committed using firearms. In 2018, suicides by firearms were the third leading cause of injury deaths in those 65 years of age and older [1]. The research on firearm-related suicides has had an emphasis on youths [2-5]. The elderly population (65 years of age and older) composed $16 \%$ of the population (52 million) in 2018 and is expected to increase to $23 \%$ (95 million) of the population by 2060 [6]. As the elderly population increases, we can expect to see a substantial increase in the number of elderly suicides using firearms unless special efforts are undertaken to reverse the current trends.

James H. Price

jprice@utnet.utoledo.edu

1 School of Population Health, University of Toledo, 43606, OH, Toledo, USA

2 Department of Public Health Sciences, New Mexico State University, NM 88003 Las Cruces, USA
The federal government recently published Healthy People 2030, health objectives to guide health interventions for the next decade [7]. The objectives listed in this document tangentially touched on firearm suicides by the elderly (e.g., reduce firearm-related deaths, reduce rates of suicides, increase the proportion of adults with depression who get treatment, etc). There are no specific objectives addressing suicides and the elderly nor firearm deaths and the elderly in Healthy People 2030. Not since the 2012 National Strategy for Suicide Prevention has the federal government focused on firearm suicides in the elderly [8].

The purpose of this narrative review and a call for action is to provide an overview of the epidemiology of firearm suicides in the elderly, examine the risk factors associated with suicide in the elderly, explore methods for preventing firearm-related suicides in the elderly, and provide recommendations for research and public health practice to prevent firearm suicides in the elderly. 


\section{Epidemiology of Firearm Suicides by the Elderly}

The Pew Research Center has estimated that $33 \%$ of the elderly own a firearm and another $12 \%$ live with someone who has a firearm [9]. Other reports have also estimated a higher rate of firearm ownership in the elderly with almost a third or more of the elderly reporting ownership of firearms and the rate of ownership is growing the fastest for the elderly $[10,11]$. Firearms in the homes of the elderly were most likely acquired when the individuals were younger. Thus, there is a high rate of firearm accessibility in the elderly population. Individuals who own firearms are not more likely than others to have a mental disorder and the evidence for protection from crime due to firearm ownership is mixed at the best. However, multiple crosssectional, psychological autopsy, and ecologic studies have shown that firearm access is a risk factor for suicide [2, $8,10,12]$. It should be noted that there is no upper age limit for legally owning a firearm. Laws do not specifically address elderly adults with firearms who are developing diminishing capacities. However, federal law does prohibit mentally incompetent individuals from owning a firearm, a finding that must be adjudicated by the courts, in contrast to the diagnosis of dementia by a physician $[10,11]$.

The data we analyzed was from the Centers for Disease Control and Prevention's Web-based Injury Statistics Query and Reporting System (WISQARS) for the years 2010 through 2018 . We used ages 65 years and older as our definition of elderly. The vast majority $(70 \%)$ of elderly suicides in 2018 were committed using a firearm (Fig. 1a). A little over 17 elderly individuals die every day by suicide using a firearm [1]. An examination of the change in the prevalence of firearm suicides by the elderly between 2010 and 2018 found there was a $49 \%$ increase in such suicides (Table 1). In contrast, the increase in the elderly population during the same time frame was $30 \%$. From 2010 to 2018 , a total of 47,725 elderly adults committed suicide using a firearm. Of the 6375 firearm suicides in $2018,89 \%$ were committed by white males $(n=5644)$. In the same year, the rate of elderly male firearm suicides was $24.96 / 100,000$ compared to a rate of $1.92 / 100,000$ for elderly females, a rate ratio of 13 to 1 for males compared to females [1].

Previous research using the National Violent Death Reporting System (NVDRS) found that elderly men who committed suicide using a firearm were typically white, married, veterans, had physical health problems, were from rural areas, less likely to have prior suicide attempts, and were more likely to live in Southern states [8, 10, 13]. Firearms are the leading method for committing suicide in both rural and urban areas for males. Also, other studies have found that the elderly are more likely to have firearms in their homes if they have less than high school education, live in rural areas, or have an income below the poverty level, all of these being risk factors for firearm suicides $[10,14]$. NVDRS studies have also found that the majority $(>50 \%)$ of homicides by the elderly are followed by suicides and in most cases, involve an intimate partner (despite the very low rates of homicides committed by the elderly). A confluence of risk factors is often observed with elderly firearm suicides and they are described in the next section [10-13].

\section{Risk factors for Firearm Suicides}

Firearm-related suicides in the elderly, first and foremost, requires easy access to a firearm, preferably a handgun [15]. As mentioned earlier, $45 \%$ of the elderly have access to firearms [9]. Research has consistently found that the presence of a firearm in the home increases the risk of suicide of the residents by a factor of 2 to 5 times the suicide rate of homes without firearms $[16,17]$. Firearms are the most lethal form of suicide with a case fatality rate of approximately $90 \%$. The elderly plan suicides with greater intent and lethality $[10,18]$. The high suicide fatality rate in the elderly is likely compounded by the frailty of many elderly and the fact that many of them live alone. The other risk factors associated with suicide in the elderly can be grouped into three categories: mental health issues, social issues, and physical health issues.

Of the three groups of issues, mental health issues are most consistently and highly correlated with suicides in the elderly. Psychiatric disorders have been found in 51-97\% of elderly suicides $[19,20]$. The largest number of individuals with mental health issues who commit suicides are those diagnosed with a major depressive disorder [19-24]. A recent study found that $27 \%$ of suicide deaths were attributed to major depression and $22 \%$ to anxiety disorders [19]. Bipolar and schizophrenia spectrum disorders have the highest relative risk of suicide deaths, but both groups consist of smaller numbers of individuals with these disorders. They account for $8 \%$ and $2 \%$ of the suicides, respectively [19]. Also, neurocognitive disorders of the prefrontal cortex, an area of the brain responsible for executive decision making, have been associated with elderly suicides. These individuals may have poor problem-solving skills, lack insight into the consequences of their decisions, and diminished restraint over their thoughts and actions [22, 23]. Given the aging population, a salient example of neurocognitive issues is dementia disorders (e.g. Alzheimer's). In addition to confusion, personality changes, anxiety, and profound cognitive deficits, such disorders may be accompanied by aggressive and violent impulsive behaviors. Access to firearms may 
Fig. 1 Suicides and firearms deaths in the elderly, 2018

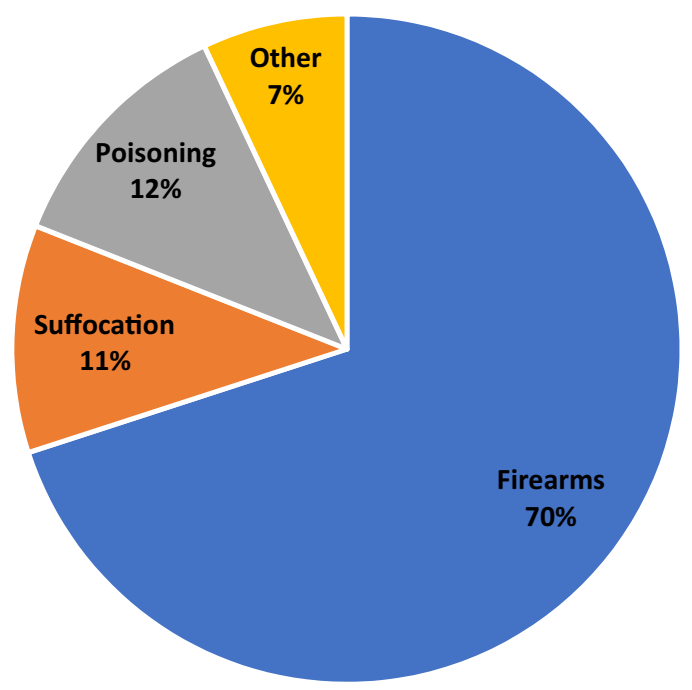

A Suicide Deaths in the Elderly $(n=9,102)$

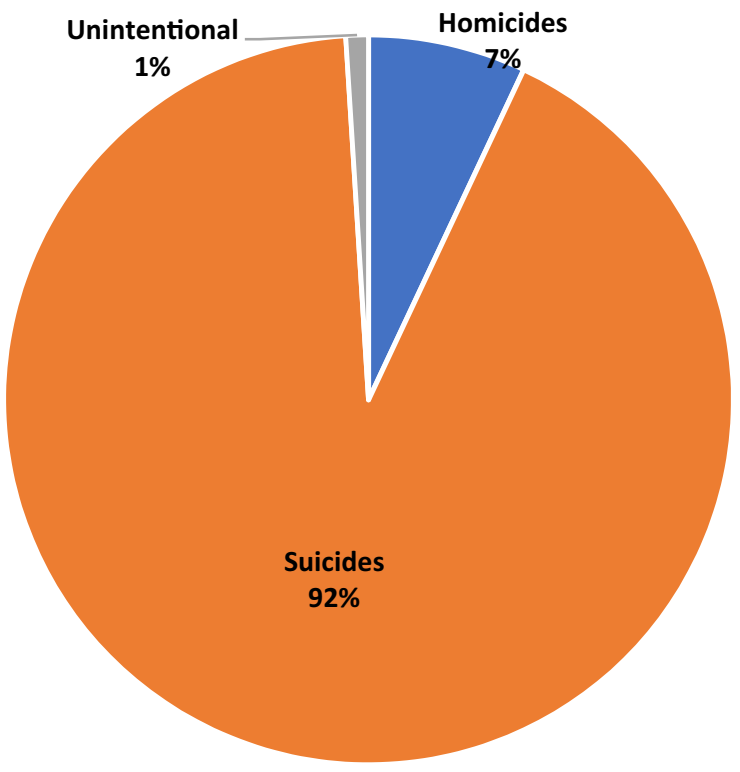

B Firearm Deaths in the Elderly, $2018(n=6,375)$

\section{Source: CDC Web-based Injury Statistics Query and Reporting System}

pose a dual danger for both the elderly with these disorders and their caretakers and family members $[10,11,22$, 25]. Personality traits have also been associated with elderly subjects who commit suicide. Such attributes as conservative views, emotional constriction, a lack of willingness to try new things, and cognitive rigidness may preclude successful adaptation to many of the stresses associated with the aging process [24-26]. In the case of elderly males, the psychological constructs of what it means to "be a man" (e.g. strong, independent, sexual aggressor, etc.) may be confronted by the vagaries of aging, impairing positiveness of future orientation and increasing thoughts of suicide.

In the category of social issues impacting suicides, it is the stress-inducing variables of life that can predispose some individuals, especially males, to perceive suicide as a suitable solution to their stresses. For some, these stressful life 
Table 1 Firearm suicides in the elderly, 2010-2018

\begin{tabular}{llll}
\hline Year & Total & $\begin{array}{l}\text { Males } \\
\mathrm{n}(\%)\end{array}$ & $\begin{array}{l}\text { Females } \\
\mathrm{n}(\%)\end{array}$ \\
\hline 2018 & 6375 & $5817(91)$ & $558(9)$ \\
2017 & 5996 & $5491(92)$ & $505(8)$ \\
2016 & 5756 & $5230(91)$ & $526(9)$ \\
2015 & 5511 & $5039(91)$ & $472(9)$ \\
2014 & 5376 & $4920(92)$ & $456(8)$ \\
2013 & 5113 & $4666(91)$ & $447(9)$ \\
2012 & 4796 & $4391(92)$ & $405(8)$ \\
2011 & 4526 & $4142(92)$ & $384(8)$ \\
2010 & 4276 & $3932(92)$ & $344(8)$ \\
Total & 47,725 & $43,628(91)$ & $4097(9)$ \\
\hline
\end{tabular}

Source: CDC Web-based Injury Statistics Query and Reporting System

events tend to accumulate and may be perceived to be more severe than others might perceive them to be, especially in light of fewer resources available to some of the elderly. Loss of best friends who move away, loss of the life of a spouse or children (bereavement), loss of relationships with family members, are all the stresses that may reduce the meaning of life [20]. Other social factors that may increase elderly suicides include loss of a job, especially for males who identify themselves as their jobs (e.g. firemen, farmers, vice-president, etc.), with loss of a job loss of belongingness may occur [27]. Also, with the loss of a job, including retirements, some may have a pronounced loss of financial resources. The median income of the elderly in 2018 was a little over \$25,000 [6]. Many older workers believe Social Security (SS) income will provide adequate income during retirement. In reality, SS's average benefit in 2018 was almost $\$ 1,300$ per month. In the same year, approximately $10 \%$ of the elderly lived below the poverty line and those who lived alone had rates of poverty exceeding $11 \%$ [6]. Not having sufficient financial resources may cause adult males to perceive themselves as a burden to their family members and/or society, leading to elderly suicides [28]. Additionally, limited financial resources may contribute to social isolation and increased loneliness [29]. For many elderly people, being lonely, isolated, and with fewer resources makes them less likely to reach out for support and assistance compared to their counterparts.

The third category of suicide risk factors, physical health issues, includes a variety of illnesses and their sequela. A review of chronic physical illnesses and suicides found that elderly individuals with such diagnoses were three times more likely to commit suicide than elderly subjects without such diagnoses [30]. A review of 65 studies of physical illnesses and suicidal behavior in the elderly found the following illnesses to be associated with increased risk of suicide: arthritis, cancer, chronic obstructive pulmonary disease, liver disease, neurological disorders, chronic pain, and functional disabilities [31]. A more recent review and meta-analysis found that cancers increased suicidal rates in both men and women [32]. The elevated suicide standardized mortality ratios (SMRs) varied by type of cancer: colorectal $(\mathrm{SMR}=1.57)$, prostate $(\mathrm{SMR}=1.71)$, esophagus/ stomach/ pancreas/ liver $(\mathrm{SMR}=2.06)$, respiratory tract $(\mathrm{SMR}=3.07)$, breast $(\mathrm{SMR}=1.24)$ [32]. A study of cancer patients in England found the suicide risk in cancer patients was highest in the first 6 months after diagnosis [33]. However, other studies have found that functional impairments were stronger indicators of suicide risk in the elderly than physical illnesses [34, 35]. In the presence of chronic pain, men $(O R=9.9)$ were more likely to commit suicide than were women $(\mathrm{OR}=3.3)$ [30]. Many of the chronic health conditions can lead to frustration, hopelessness, loss of dignity, and loss of some pleasures in life [29-33].

\section{Prevention of Firearm-Related Suicides}

It appears from the research in the area of suicide prevention that most attempts to reduce suicides are intuitively logical rather than based on empirical research [36]. Evidence regarding the elderly and firearm suicides is mostly based on logical interventions rather than research-based interventions. To reduce the frequency of firearm-related suicides in the elderly, reducing the risk factors for suicides and enhancing the situational and contextual factors that help the elderly cope with their late-life changes are needed [34-37]. Similar to general public health prevention models, interventions for the prevention of elderly firearm suicides can be categorized as falling into two categories, interventions directed at highrisk individuals, and population-based interventions [38].

\section{Individual- Level Interventions}

One of the most studied interventions directed at high-risk individuals is anticipatory guidance by physicians regarding the safe storage of firearms for patients who own firearms. Elderly individuals who own handguns have three times the risk of firearm suicides, keeping the firearm loaded increases the risk of firearm suicides by six times, and keeping the firearm unlocked increases the risk by almost 10 times the risk of non-firearm owners [16]. A substantial portion $(82 \%)$ of older adults who die by suicide have seen a physician during the last 3 months of their lives. Yet, extensive reviews of studies on physicians, psychiatrists, and other health professionals have found that most are neither trained nor practice anticipatory guidance on firearms with patients, despite a sizeable proportion believing in the benefits of firearm safety counseling [39, 40]. Many of the elderly have an exaggerated 
fear of crime despite being less likely to be victims of violent crime. The primary reason why adults own handguns is for protection [10, 41, 42]. This may require the physician to suggest alternatives to firearms for personal safety (e.g., a pet dog, motion-sensitive external lights, house alarm systems, etc.). Another component of such a discussion should include safe storage of firearms (storing firearms unloaded and locked with ammunition stored separately). Research has shown that family physicians' brief counseling on firearm storage habits significantly improved patient firearm storage habits [43]. It is often suggested that physicians should be more aware of older adults in their practice who may be suicidal. The implication is that screening for suicide should occur in primary care practice. However, suicide prediction models have an accuracy of predicting future suicide events that is near zero [44]. The authors went on to note that $99 \%$ of the individuals predicted to die by suicide will not and they might be subjected to a risk classification that may be stigmatizing and to clinical interventions of questionable efficacy and appropriateness [44].

The stressors common to many in later life (e.g. social isolation, bereavement, insufficient financial resources, etc.) may require help from social workers and local agencies such as Meals on Wheels, Area Agencies on Aging, local senior centers, transportation agencies, energy-related assistance, and many other services. Increasing social integration of the elderly can help reduce many of the stressors that can help precipitate suicidal behaviors, especially in older males who are not good at reaching out and requesting assistance. State welfare policies (e.g., spending on public education, food for the needy, and healthcare expenditures) and poverty levels have a very modest impact on the prevalence rates or reduction of suicides [45-47]. Again, it must be emphasized that these effects are often not specific to elderly firearm suicides.

In a recent study of older adults, three-fourths of suicide decedents did not inform others of their intent to commit suicide. This study also found that almost $82 \%$ of males who committed suicide with a firearm were without a known mental illness [48]. The most frequently identified risk factor for suicide in these elderly males was a physical health problem $(54 \%)$, not a mental health problem. Other studies have found similar characteristics for elderly males who committed suicide with a firearm compared to younger individuals (i.e. less likely to have a mental health problem or history of suicide attempts) [10]. Elderly males are the individuals most likely to develop cardiovascular diseases, cancers, and chronic pain conditions, in part, due to lifestyles and aging. Thus, it may be that more elderly individuals need referrals for palliative care medicine, where those living with a serious illness may obtain some relief from their symptoms and improve the quality of their lives. Integrated and multidisciplinary clinical teams can help with treating multimorbidity and associated psychological distress in the elderly to reduce firearm suicides.

Another avenue for individual-level interventions that warrants attention is the treatment of mental illnesses, especially major affective disorders. Research indicates that physicians are less likely to screen and treat depression and suicide in the elderly, especially male patients [ 49 , 50]. It is essential to reduce elderly suicides there needs to be more mental healthcare providers who are easily accessible, affordable, and acceptable to the elderly [21]. Mental healthcare needs to be a part of primary healthcare, and for the elderly, there is a necessity for social services integration as well. While the effects are not specific to the elderly or firearms, greater healthcare services and state spending on mental healthcare have been associated inversely with the risk of suicides [45-47, 51]. Focusing not just on the quantity of the workforce, but the quality of the workforce, with special emphasis on behavioral health training and geriatric practice to address the unmet mental health needs of the elderly, can have multiplicative effects on the health and wellbeing of the elderly which may alleviate suicidal ideation or behaviors $[10,11,16,10,11]$.

Certain challenges need to be acknowledged with an overemphasis on firearm suicides due to mental illness and the complex relationship between firearms, mental illnesses, and suicides. Many firearm suicides in the elderly are not related to mental illnesses and pharmacotherapies for mental illnesses may not always reduce suicidal ideation or attempts as evidenced by many individuals who commit suicides with firearms that were being treated for mental illnesses. Also, mentally ill elderly may not always seek treatment and even if treated, they may continue to live with access to firearms. Epidemiological and clinical models solely focusing on mental illnesses cannot predict future suicide attempts very well, mental illnesses the in elderly may exist with comorbidities and substance use disorders posing a risk for suicides, and an overemphasis on mental illness may lead to stereotyping of mental illness and its association with firearm violence and suicides [19, 20, 37, 40, 44, 48, 21].

\section{Population-Based Interventions}

The population-based strategy to reduce firearm-related suicides in the elderly that has shown promise is state-level firearm laws. An evaluation of the Brady Act (mandates background checks to purchase firearms) found that after implementation of the act, suicide rates in older adults (55 years or older) were reduced [52]. Another group of firearm-related laws exists that help to protect individuals in a crisis, Extreme Risk Protective Orders (ERPOs). As of July 2020, 19 states and the District of Columbia had ERPOs, also known as "red flag" laws [53]. These laws empower families and law enforcement agencies to petition 
local courts for a civil order to temporarily remove a person's access to their firearms before they hurt themselves. Research has found that for every 10 to 20 individuals who have their firearms removed, one life is saved from suicide. Two states, Connecticut and Indiana, have shown that their ERPOs reduced firearm suicides in these states by $14 \%$ and $7.5 \%$, respectively [54]. Another law that has shown promise is permit-to-purchase (PTP) laws, which require individuals to obtain a permit from law enforcement (as well as a background check) when purchasing a handgun. Two states, Connecticut and Missouri, have had their PTPs studied. Connecticut instituted a PTP and comprehensive point of sale background check laws. Over the next decade, their firearm-related suicide rate declined $15 \%$ [55]. In the case of Missouri, the state repealed its PTP law and then experienced a $16 \%$ increase in its firearm-related suicide rate over the subsequent 5 years. It should also be noted that research has found that states with a higher number of and stronger firearm laws had lower rates of firearm-related suicides [56, 57]. A recent longitudinal study from 2012 to 2016 assessed the influence of state firearm laws on firearmrelated, non-firearm, and total suicide rates in individuals ages 55 to 64 years and ages 65 and older. The study showed that the total number of firearm laws was negatively associated with firearm-related suicide and the total number of suicides among both age groups. Similarly, ERPOs were associated with a reduction in firearm suicides $(>2 \%$ for both age groups) and a reduction in total suicide deaths in both age groups [58].

The promise of state firearm laws as it relates to firearm suicides in the elderly is marred by several limitations [56-61]. First, most studies on firearm laws and suicides do not exclusively focus on the elderly population, a major limitation given the unique socioeconomic and lifestyle circumstances of the elderly. Second, most of the studies use ecological approaches precluding the establishment of a causal relationship between laws and suicide mortality. Third, statewide variations in firearm laws and their enforcement, along with the sociodemographic composition of states make the investigation of firearm suicides in the elderly very complex. Fourth, laws pertain to individuals. Many of the laws are either not fully investigated by researchers or are so complicated that healthcare providers and caregivers may find them difficult to comprehend and utilize (e.g., temporary transfer of firearms from home to prevent suicides). Along the same lines, there is a question about how many family members or healthcare providers of the elderly would be willing to engage in legal options to remove firearms from the elderly. Finally, laws are only as good as they can be applied or interpreted. In the case of firearms and elderly suicides, there are several potential loopholes such as: individuals with serious mental illnesses or substance use disorders can still access guns, the databases with records on individuals with serious mental illness may be incomplete, there are multiple laws and databases that lack coordination and individuals slip through the cracks, physicians and law enforcement officials may not always have the ability or knowledge to utilize firearm laws to help remove firearms from elderly individuals at risk of suicide, firearm prohibitions for mental illness or substance use disorders do not last for a lifetime, the scope of existing firearm laws remains narrow and these laws are frequently challenged in courts. [12, 16, 17, 37, 40, 56-61].

\section{Implications}

Our data and review establish a few key facts; firearm suicides are the leading method of elderly suicidal deaths. The number of elderly firearm suicides is increasing with a greater burden in males. Firearm ownership is closely associated with firearm suicides, and currently, few clinical and population-based interventions have been tested and evaluated or found to be effective in reducing elderly firearm suicides.

Implications of this review must also be considered in light of the COVID-19 pandemic which may have a drastic impact on the socio-economic conditions of the elderly in the U.S. and the risk of firearm suicides [28, 62]. It has been estimated that COVID- 19 related poverty, debts, and financial insecurities may also influence elderly health, wellbeing, and risk of suicides given the experiences from previous economic downturns. Therefore, the reduction of firearm-related suicides in the elderly would need interdisciplinary and multisectoral approaches that are both population-based and individual-level (e.g., clinical). Essentially, these approaches will have to consider the three facets of the Interpersonal Theory of Suicide (i.e., reduce thwarted belongingness, perceived burdensomeness to society, and capability of suicide) [22, 26, 27, 62]. First, continued engagement of elderly individuals in community activities and social services via rapid expansion of multimodal psychosocial interventions may have multiplier effects on the health and wellbeing of the elderly in addition to the potential reduction in self-harm. Government agencies and community organizations can play a lead role in such initiatives. Second, increasing access to geriatric and psychiatric care may have benefits, even if modest, in reducing the burden of firearm suicides in the elderly (based on studies mentioned earlier that have highlighted the association between state mental health spending, behavioral workforce capabilities, and extent of psychiatric services on suicides, including those committed with firearms). Third, income and family welfare services should focus on the most marginalized and disadvantaged elderly who are at risk of greater perceived burdensomeness and capability of suicide linked to 
poverty and material deprivation. Information technology and telemedicine play a key role in all the aforementioned practice implications. Finally, as it relates to state firearm laws, expansion of laws across states and widening the focus of existing laws to ensure a broader outreach to the elderly should be advocated for. Additional legal powers and outreach efforts by clinicians, family members, and law enforcement agencies should be explored in helping remove firearms from the elderly who: are at risk for suicides, have a history of suicide attempts, are diagnosed with serious mental illness and substance use disorders, or have been held involuntarily for mental illness or examination related to mental illness [10, 37, 40, 49].

Additional research is needed not just to reduce suicidal ideation, but completed suicides. A couple of trials and studies were found in our review (e.g., PROSPECT trial and EPOCH study) that employed interventions to improve behavioral healthcare, mental health outcomes, and to reduce suicidal ideation [63, 64]. Similarly, several longitudinal studies of aging in the U.S. can include suicide attempts and completed suicides as major outcomes in these studies (e.g., Longitudinal Study of Aging and Health and Retirement Study). Research focusing on handgun ownership, safe storage and removal counseling, the effect of firearm legislation and laws on suicides, means restriction, suicide prediction modeling, and influence of past suicide attempts should be designed to exclusively focus on the elderly in the U.S with greater emphasis on exploration of correlates such as sociodemographic, lifestyle, firearm-related behaviors, and health conditions of older adults to study elderly firearm suicide with greater accuracy [65-67]. Given the increasing amount of frailty and cognitive declines faced by many elderly, additional areas of research include studies on advance planning, better use of gun trusts and safety technology, outreach methods to promote elderly inclusion in voluntary do not sell lists, planning for future means restriction, retirement planning for firearms along with financial and social planning, and options for changes in advance directives to ensure that those who are not capable of safely handling a firearm have reduced access to firearms [63-67]. In these strategies, it is also crucial to know how to better reach out to the elderly who are at risk of firearm suicides and the approaches could be multimodal (e.g., family members, healthcare providers, or dementia organizations, etc.) [65-68]. In a recent national study of more than 1000 elderly Americans (who were firearm owners or were in homes with firearms), only a fifth of older firearm owners reported having a plan for securing, removing, or transferring firearms if they became unable to handle them safely [68]. The effect and uptake of such measures to reduce firearm suicides in the elderly need additional research and prospective studies [66-68].

\section{Conclusions}

As the population ages we are going to see firearm-related suicides become a more prominent and frequent public health problem, especially as more people purchase handguns and people are living longer. Also, the elderly usually engage in suicidal behaviors with greater planning and lethality of intent than young adults. Suicide in the elderly should never be assumed to be a normative response just because many have accumulated significant physical insult to their bodies and stressors over a lifespan. Unfortunately, firearm-related suicide in the elderly has received much less attention (ageism) than that received for youths and younger adults. To reduce suicides in the elderly we must first and foremost deal with the impact of firearms on the suicide rate of the elderly, especially elderly males. To date, the research points to state firearm legislation and improving mental health services as the most promising interventions for reducing firearm-related suicide in general. It is not clear how well these strategies will specifically impact elderly suicides. Furthermore, the functional lifespan of a firearm can be measured in decades. This fact may imply that many elderly individuals who own handguns that will be used in their suicides did not go out and buy them recently. Thus, interventions to restrict access to already purchased firearms by the elderly need to be implemented and evaluated. This form of individual intervention may supplement the effects of the population approach offered by state firearm laws.

Funding This research received no external funding.

\section{Compliance with Ethical Standards}

Conflict of interest Authors have no conflicts of interests to declare.

\section{References}

1. Centers for Disease Control and Prevention. (2020). Fatal and non-fatal injury data. Web-based Injury Statistics Query and Reporting System (WISQARS). Retrieved November 27th, 2020, from https://www.cdc.gov/injury/wisqars/index.html.

2. Price, J. H., \& Khubchandani, J. (2017). Adolescent homicides, suicides, and the role of firearms: A narrative review. American Journal of Health Education, 48(2), 67-79.

3. Price, J. H., \& Khubchandani, J. (2017). Latina adolescents health risk behaviors and suicidal ideation and suicide attempts: Results from the National Youth Risk Behavior Survey 2001-2013. Journal of Immigrant and Minority Health, 19(3), 533-542.

4. Price, J. H., \& Khubchandani, J. (2019). The changing characteristics of African-American adolescent suicides, 2001-2017. Journal of Community Health, 44(4), 756-763.

5. Kivisto, A. J., Kivisto, K. L., Gurnell, E., Phalen, P., \& Ray, B. (2020). Adolescent suicide, household firearm ownership, and the 
effects of child access prevention laws. Journal of the American Academy of Child \& Adolescent Psychiatry. In press. https://doi. org/10.1016/j.jaac.2020.08.442.

6. Administration for Community Living. 2019 profiles of older Americans. Administration on Aging, U.S. Department of Health and Human Services. Retrieved October 30th, 2020, from https:// acl.gov/aging-and-disability-in-america/data-and-research/profi le-older-americans.

7. US Department of Health and Human Services. Healthy People 2030. Retrieved October 4th, 2020 from https://health.gov/healt hypeople.

8. Office of the Surgeon General (2012). 2012 national strategy for suicide prevention: goals and objectives for action: A report of the US Surgeon General and of the National Action Alliance for Suicide Prevention. Retrieved November 17th, 2020 from https:// www.ncbi.nlm.nih.gov/books/NBK109917/.

9. Parker, K., Horowitz, J. M., Igielnik, R., Oliphant, J. B., \& Brown, A. (2017). America's complex relationship with guns. Pew Research Center 2017. Retrieved October 4th, 2020 from https:// www.pewsocialtrends.org/2017/06/22/the-demographics-of-gunownership/.

10. Mertens, B., \& Sorenson, S. B. (2012). Current considerations about the elderly and firearms. American Journal of Public Health, 102(3), 396-400.

11. Greene, E., Bornstein, B. H., \& Dietrich, H. (2007). Granny, (don't) get your gun: competency issues in gun ownership by older adults. Behavioral Sciences \& the Law, 25(3), 405-423.

12. Miller, M., Barber, C., White, R. A., \& Azrael, D. (2013). Firearms and suicide in the United States: is risk independent of underlying suicidal behavior? American Journal of Epidemiology, 178(6), 946-955.

13. Kaplan, M. S., Huguet, N., McFarland, B. H., \& Mandle, J. A. (2012). Factors associated with suicide by firearm among US older adult men. Psychology of Men \& Masculinity, 13(1), 65.

14. Lum, H. D., Flaten, H. K., \& Betz, M. E. (2016). Gun access and safety practices among older adults. Current Gerontology and Geriatrics Research. https://doi.org/10.1155/2016/2980416.

15. Hanlon, T. J., Barber, C., Azrael, D., \& Miller, M. (2019). Type of firearm used in suicides: findings from 13 states in the national violent death reporting system, 2005-2015. Journal of Adolescent Health, 65(3), 366-370.

16. Conwell, Y., Duberstein, P. R., Connor, K., Eberly, S., Cox, C., $\&$ Caine, E. D. (2002). Access to firearms and risk for suicide in middle-aged and older adults. American Journal of Geriatric Psychiatry, 10(4), 407-416.

17. Miller, M., Warren, M., Hemenway, D., \& Azrael, D. (2015). Firearms and suicide in US cities. Injury Prevention, 2l(e1), e116-e119.

18. Shenassa, E. D., Catlin, S. N., \& Buka, S. L. (2003). Lethality of firearms relative to other suicide methods: A population-based study. Journal of Epidemiology \& Community Health, 57(2), 120-124.

19. Yeh, H. H., Westphal, J., Hu, Y., Peterson, E. L., Williams, L. K., et al. (2019). Diagnosed mental health conditions and risk of suicide mortality. Psychiatric Services, 70(9), 750-757.

20. Conwell, Y., Van Orden, K., \& Caine, E. D. (2011). Suicide in older adults. Psychiatric Clinics, 34(2), 451-468.

21. Conwell, Y. (2014). Suicide later in life: challenges and priorities for prevention. American Journal of Preventive Medicine, 47(3), S244-S250.

22. Schmutte, T., O'Connell, M., Weiland, M., Lawless, S., \& Davidson, L. (2009). Stemming the tide of suicide in older white men: a call to action. American Journal of Men's Health, 3(3), 189-200.
23. Conejero, I., Olié, E., Courtet, P., \& Calati, R. (2018). Suicide in older adults: Current perspectives. Clinical Interventions in Aging, 13, 691-699.

24. Elderkin-Thompson, V., Mintz, J., Haroon, E., Lavretsky, H., \& Kumar, A. (2007). Executive dysfunction and memory in older patients with major and minor depression. Archives of Clinical Neuropsychology, 22(2), 261-270.

25. Marzuk, P. M., Hartwell, N., Leon, A. C., \& Portera, L. (2005). Executive functioning in depressed patients with suicidal ideation. Acta Psychiatrica Scandinavica, 112(4), 294-301.

26. Useda, J. D., Duberstein, P. R., Conner, K. R., Beckman, A., Franus, N., Tu, X., \& Conwell, Y. (2007). Personality differences in attempted suicide versus suicide in adults 50 years of age or older. Journal of Consulting and Clinical Psychology, 75(1), 126-133.

27. Van Orden, K. A., Witte, T. K., Cukrowicz, K. C., Braithwaite, S. R., Selby, E. A., \& Joiner, T. E. Jr. (2010). The interpersonal theory of suicide. Psychological Review, 117(2), 575-600.

28. Duberstein, P. R., Conwell, Y., Conner, K. R., Eberly, S., \& Caine, E. D. (2004). Suicide at 50 years of age and older: perceived physical illness, family discord and financial strain; Life events and suicide at age 50 and older. Psychological Medicine, 34(1), 137-146.

29. Baumeister, R. F., \& Leary, M. R. (1995). The need to belong: desire for interpersonal attachments as a fundamental human motivation. Psychological Bulletin, 117(3), 497-529.

30. Juurlink, D. N., Herrmann, N., Szalai, J. P., Kopp, A., \& Redelmeier, D. A. (2004). Medical illness and the risk of suicide in the elderly. Archives of Internal Medicine, 164(11), 1179-1184.

31. Fässberg, M. M., Cheung, G., Canetto, S. S., Erlangsen, A., Lapierre, S., Lindner, R., \& Duberstein, P. (2016). A systematic review of physical illness, functional disability, and suicidal behaviour among older adults. Aging \& Mental Health, 20(2), 166-194.

32. Amiri, S., \& Behnezhad, S. (2020). Cancer diagnosis and suicide mortality: a systematic review and meta-analysis. Archives of Suicide Research, 24(sup2), S94-S112.

33. Henson, K. E., Brock, R., Charnock, J., Wickramasinghe, B., Will, O., \& Pitman, A. (2019). Risk of suicide after cancer diagnosis in England. JAMA Psychiatry, 76(1), 51-60.

34. Kaplan, M. S., McFarland, B. H., Huguet, N., \& Newsom, J. T. (2007). Physical illness, functional limitations, and suicide risk: A population-based study. American Journal of Orthopsychiatry, 77(1), 56-60.

35. Conwell, Y., Duberstein, P. R., Hirsch, J. K., Conner, K. R., Eberly, S., \& Caine, E. D. (2010). Health status and suicide in the second half of life. International Journal of Geriatric Psychiatry: A Journal of the Psychiatry of Late Life and Allied Sciences, 25(4), 371-379.

36. Platt, S., \& Niederkrotenthaler, T. (2020). Suicide prevention programs. Crisis., 41(suppl 1), S99-S124. https://doi. org/10.1027/0227-5910/a000671.

37. Swanson, J. W. (2020). Preventing suicide through better firearm safety policy in the United States. Psychiatric Services, appi-ps. https://doi.org/10.1176/appi.ps.202000317.

38. Rose, G. (1981). Strategy of prevention: lessons from cardiovascular disease. British Medical Journal (Clinical research ed.), 282(6279), 1847-1851.

39. Roszko, P. J., Ameli, J., Carter, P. M., Cunningham, R. M., \& Ranney, M. L. (2016). Clinician attitudes, screening practices, and interventions to reduce firearm-related injury. Epidemiologic Reviews, 38(1), 87-110.

40. Price, J. H., \& Khubchandani, J. (2016). Firearm violence by the mentally ill: Mental health professionals' perceptions and practices. Violence and Gender, 3(2), 92-99. 
41. Ross, C. E., \& Jang, S. J. (2000). Neighborhood disorder, fear, and mistrust: The buffering role of social ties with neighbors. American Journal of Community Psychology, 28(4), 401-420.

42. Siegel, M. B., \& Boine, C. C. (2020). The meaning of guns to gun owners in the US: the 2019 National Lawful Use of Guns Survey. American Journal of Preventive Medicine, 59(5), 678-685.

43. Albright, T. L., \& Burge, S. K. (2003). Improving firearm storage habits: impact of brief office counseling by family physicians. Journal of the American Board of Family Practice, 16(1), 40-46.

44. Belsher, B. E., Smolenski, D. J., Pruitt, L. D., Bush, N. E., Beech, E. H., Workman, D. E., \& Skopp, N. A. (2019). Prediction models for suicide attempts and deaths: a systematic review and simulation. JAMA Psychiatry, 76(6), 642-651.

45. Goldstein, E. V., Prater, L. C., \& Wickizer, T. M. (2019). Behavioral health care and firearm suicide: Do states with greater treatment capacity have lower suicide rates? Health Affairs, 38(10), $1711-1718$.

46. Gibbons, R. D., Hur, K., \& Mann, J. J. (2017). Suicide rates and the declining psychiatric hospital bed capacity in the United States. JAMA Psychiatry, 74(8), 849-850.

47. Rambotti, S. (2020). Is there a relationship between welfare-state policies and suicide rates? Evidence from the US states, 20002015. Social Science \& Medicine, 246, 112778.

48. Schmutte, T. J., \& Wilkinson, S. T. (2020). Suicide in older adults with and without known mental illness: Results from the National Violent Death Reporting System, 2003-2016. American Journal of Preventive Medicine, 58(4), 584-590.

49. Simons, K., Van Orden, K., Conner, K. R., \& Bagge, C. (2019). Age differences in suicide risk screening and management prior to suicide attempts. American Journal of Geriatric Psychiatry, 27(6), 604-608.

50. Kato, E., Borsky, A. E., Zuvekas, S. H., Soni, A., \& Ngo-Metzger, Q. (2018). Missed opportunities for depression screening and treatment in the United States. Journal of The American Board of Family Medicine, 31(3), 389-397.

51. Lang, M. (2013). The impact of mental health insurance laws on state suicide rates. Health Economics, 22(1), 73-88.

52. Ludwig, J., \& Cook, P. J. (2000). Homicide and suicide rates associated with implementation of the Brady Handgun Violence Prevention Act. Journal of the American Medical Association, 284(5), 585-591.

53. Giffords Law Center to Prevent Gun Violence. Extreme Risk Protection Orders (2020). Retrieved October 4th 2020 from https ://giffords.org/lawcenter/gun-laws/policy-areas/who-can-have-agun/extreme-risk-protection-orders/.

54. Kivisto, A. J., \& Phalen, P. L. (2018). Effects of risk-based firearm seizure laws in Connecticut and Indiana on suicide rates, 1981-2015. Psychiatric Services, 69(8), 855-862.

55. Crifasi, C. K., Meyers, J. S., Vernick, J. S., \& Webster, D. W. (2015). Effects of changes in permit-to-purchase handgun laws in Connecticut and Missouri on suicide rates. Preventive Medicine, $79,43-49$.

56. Fleegler, E. W., Lee, L. K., Monuteaux, M. C., Hemenway, D., \& Mannix, R. (2013). Firearm legislation and firearm-related fatalities in the United States. JAMA Internal Medicine, 173(9), 732-740.
57. Kaufman, E. J., Morrison, C. N., Branas, C. C., \& Wiebe, D. J. (2018). State firearm laws and interstate firearm deaths from homicide and suicide in the United States: A cross-sectional analysis of data by county. JAMA Internal Medicine, 178(5), 692-700.

58. Saadi, A., Choi, K. R., Takada, S., \& Zimmerman, F. J. (2020). The impact of gun violence restraining order laws in the US and firearm suicide among older adults: a longitudinal state-level analysis, 2012-2016. BMC public health, 20, 1-8.

59. Gibbons, M. J., Fan, M. D., Rowhani-Rahbar, A., \& Rivara, F. P. (2020). Legal liability for returning firearms to suicidal persons who voluntarily surrender them in 50 US states. American Journal of Public Health, 110(5), 685-688.

60. McCourt, A. D., Vernick, J. S., Betz, M. E., Brandspigel, S., \& Runyan, C. W. (2017). Temporary transfer of firearms from the home to prevent suicide: legal obstacles and recommendations. JAMA Internal Medicine, 177(1), 96-101.

61. Frattaroli, S., Hoops, K., Irvin, N. A., McCourt, A., Nestadt, P. S., Omaki, E., \& Wilcox, H. C. (2019). Assessment of physician self-reported knowledge and use of Maryland's Extreme Risk Protection Order Law. JAMA Network Open, 2(12), e1918037-e1918037.

62. Sheffler, J. L., Joiner, T. E., \& Sachs-Ericsson, N. J. (2020). The interpersonal and psychological impacts of COVID-19 on risk for late-life suicide. The Gerontologist. https://doi.org/10.1093/geron t/gnaa103.

63. Cook, J. M., Pearson, J. L., Thompson, R., Black, B. S., \& Rabins, P. V. (2002). Suicidality in older African Americans: findings from the EPOCH study. American Journal of Geriatric Psychiatry, 10(4), 437-446.

64. Alexopoulos, G. S., Reynolds, C. F., Bruce, M. L., Katz, I. R., Raue, P. J., \& Mulsant,. (2009). Reducing suicidal ideation and depression in older primary care patients: 24-month outcomes of the PROSPECT study. American Journal of Psychiatry, 166(8), 882-890.

65. Vars, F. E. (2020). Voluntary do-not-sell lists-an innovative approach to reducing gun suicides. New England Journal of Medicine, 383(14), 1299-1301.

66. Betz, M. E., Azrael, D., Johnson, R. L., Knoepke, C. E., Ranney, M. L., Wintemute, G. J., \& Miller, M. (2020). Views on firearm safety among caregivers of people with Alzheimer disease and related dementias. JAMA Network Open, 3(7), e207756-e207756.

67. Morgan, E. R., \& Rowhani-Rahbar, A. (2020). Firearm safety in an aging United States. JAMA Network Open, 3(7), e2011182-e2011182.

68. Betz, M. E., Miller, M., Matlock, Md., \& D. D., Wintemute, G. J., Johnson, R. L., Grogan, C., Azrael, D. (2020). Older firearm owners and advance planning: Results of a national survey. Annals of Internal Medicine. https://doi.org/10.7326/M20-2280.

Publisher's note Springer Nature remains neutral with regard to jurisdictional claims in published maps and institutional affiliations. 